\title{
Extended high-frequency audiometry in healthy adults with different age groups
}

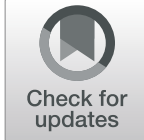

Mingming Wang ${ }^{1} \mathbb{D}$, Yu $\mathrm{Ai}^{2}$, Yuechen Han ${ }^{1}$, Zhaomin Fan ${ }^{1}$, Peng Shi ${ }^{3^{*}}$ and Haibo Wang ${ }^{\text {* }^{*}}$

\begin{abstract}
Background: It was well-documented that extended high-frequency (EHF, above $8 \mathrm{kHz}$ ) hearing test could be more sensitive comparing with the conventional measurement on frequency below $8 \mathrm{kHz}$, regarding the early prediction of auditory damage in certain population. However, hardly any age-specific thresholds of EHF in population with normal hearing ability were observed. This study aims to monitor the age-dependent hearing thresholds at EHF (from 9 to $20 \mathrm{kHz}$ ) in healthy hearing population.
\end{abstract}

Methods: A total of 162 healthy participants (from 21 to 70 years) with normal conventional pure tone audiograms were recruited and separated into five groups by age. Conventional pure tone average was performed with frequencies from 0.25 to $8 \mathrm{kHz}$ under air conduction and from 0.25 to $4 \mathrm{kHz}$ under bone conduction. EHF audiometry from 9 to $20 \mathrm{kHz}$ was determined under air conduction.

Results: The effects of aging on hearing were evident at frequencies above $4 \mathrm{kHz}$. The hearing thresholds of EHF were less than $26 \mathrm{~dB}$ HL before 30 years-olds. Hearing abilities in EHF were deteriorated starting from the $31 \sim 40$ group and were most obvious in the $51 \sim 60$ group and the $61 \sim 70$ group with the maximum thresholds of $75 \mathrm{~dB} \mathrm{HL}$. Sensitivity of EHF was inversely proportional to the frequency within each age group, and to age among groups. Subjects under 30 years old were totally responsive up to $16 \mathrm{kHz}$, and $52.2 \%$ could respond to $20 \mathrm{kHz}$. Meanwhile, no responsiveness was recorded to $20 \mathrm{kHz}$ in the $51 \sim 60$ group and even to $18 \mathrm{kHz}$ in the $61 \sim 70$ group. No gender differences in hearing threshold was observed within each age group, except an obvious decline at frequencies of $4,6,8$, and $9 \mathrm{kHz}$ in male participants of the $41 \sim 50$ group.

Conclusions: Hearing thresholds at EHF from 9 to $20 \mathrm{kHz}$ were more sensitive than at frequencies below $8 \mathrm{kHz}$ for hearing measurement, and aging inversely affected hearing ability at EHF in healthy population. Hearing thresholds at EHF deteriorated with age and raising frequency, while the upper frequency limit decreased with aging.

Keywords: Hearing threshold, Extended high frequency, Age

\section{Introduction}

The conventional method of measuring pure tone average (PTA) of hearing thresholds is performed under the frequencies lowing than $8 \mathrm{kHz}$. However, this conventional audiometry has been suggested not reliable on

\footnotetext{
*Correspondence: ship1998@163.com; whboto11@163.com

${ }^{3}$ Department of Breast and Thyroid Surgery, Shandong Provincial Hospital Affiliated to Shandong First Medical University, 324 Jingwu Road, Jinan,

China

'Department of Otorhinolaryngology Head and Neck Surgery, Shandong Provincial ENT Hospital, Cheeloo College of Medicine, Shandong University, Jinan, China

Full list of author information is available at the end of the article
}

evaluating auditory damage due to the absence of detecting responses at extended high frequencies (EHF) above $8 \mathrm{kHz}$. Monitoring EHF responses, on the other hand, could be quite useful in the early prediction of hearing loss in certain populations [1-4]. Research has demonstrated that measuring the hearing sensitivity at EHF could be useful for monitoring the auditory function in patients undertaken ototoxic agents, because the changes in EHF hearing occurred prior to changes of conventional measurements at frequencies below $8 \mathrm{kHz}$ $[5,6]$. The validity of the use of EHF is still controversial, although there has been some additional research out

(c) The Author(s). 2021 Open Access This article is licensed under a Creative Commons Attribution 4.0 International License, which permits use, sharing, adaptation, distribution and reproduction in any medium or format, as long as you give appropriate credit to the original author(s) and the source, provide a link to the Creative Commons licence, and indicate if changes were made. The images or other third party material in this article are included in the article's Creative Commons licence, unless indicated otherwise in a credit line to the material. If material is not included in the article's Creative Commons licence and your intended use is not permitted by statutory regulation or exceeds the permitted use, you will need to obtain permission directly from the copyright holder. To view a copy of this licence, visit http://creativecommons.org/licenses/by/4.0/. The Creative Commons Public Domain Dedication waiver (http://creativecommons.org/publicdomain/zero/1.0/) applies to the data made available in this article, unless otherwise stated in a credit line to the data. 
that supports use of it in detection of the noise-induced hearing loss (NIHL) [2, 7, 8]. Antonioli suggested that the EHF audiometry might not be an optimal tool to identify NIHL [9]. The hearing thresholds at EHF had also been suggested to be a good parameter in predicting difficulty in understanding speech in noise, in patients whose hearing abilities that are deemed to be normal by conventional PTA evaluation [10].

Studies with multivariate analysis proved that age was the primary factor of changes to hearing thresholds at EHF $[11,12]$. Aging was tightly correlated with the prediction of hearing impairment, even after the adjustment of other important risking factors. It has been shown that the age-related hearing change appeared first at EHF rather than at the lower frequencies [13]. The sensitivity of hearing at EHF worsened with increased age at a rate faster than that at frequencies below $8 \mathrm{kHz}$, and the inter-subject variability of pure-tone thresholds at EHF was higher than that at frequencies below $8 \mathrm{kHz}[7$, 14-17].

With the limitations of interpretations that can be made by conventional PTA, EHF audiometry had been performed more often as hearing parameters for clinical and laboratory diagnoses change with research. However, hardly any age-dependent normal audiometric thresholds at EHF from 9 to $20 \mathrm{kHz}$ had been reported up to now. Hence, the present study aimed to provide the data of hearing thresholds at frequencies up to 20 $\mathrm{kHz}$ of different age groups in the health population to serve the need.

\section{Methods}

\section{Subjects and grouping}

Adults with normal PTA hearing thresholds $(\leq 20 \mathrm{~dB}$ $\mathrm{HL}$, up to $2 \mathrm{kHz}$ ), aged between 21 to 70 years old, were recruited in the study. Subjects were in a normal state of health, free from all signs or symptoms of ear diseases. They performed ear canal cleaning before testing. No history of noise exposure (including military, occupational and recreational noise exposures), smoking, intake of alcohol and ototoxic drugs (including loop diuretics, nonsteroidal anti-inflammatory drugs, antibiotics, chemotherapeutic agents, quinine, and acetaminophen) [18], hypertension, diabetes, or familial hearing loss was reported by the subjects. All participants had healthy tympanic membranes, evaluated by otoscopy, and normal middle-ear function by immittance test (pressure between -50 and $50 \mathrm{daPa}$, and immittance between 0.3 and $1.6 \mathrm{cc}$ ). Participants were grouped according to their age as the following five categories: $21 \sim 30$ years, $31 \sim$ 40 years, $41 \sim 50$ years, $51 \sim 60$ years, or $61 \sim 70$ years. All test procedures were performed using a non-invasive technique, and were explained to all participants before testing. Informed consent was taken from each participant before data collection.

\section{Hearing assessment}

Audiometric tests were conducted by experienced technicians. Hearing thresholds of each ear at 15 frequencies from 0.25 to $20 \mathrm{kHz}$ were obtained using a pulsed-tone stimulus and modified Hughson-Westlake procedure. Conventional PTA (at $0.25 \mathrm{kHz}, 0.5 \mathrm{kHz}, 1 \mathrm{kHz}, 2 \mathrm{kHz}$, $4 \mathrm{kHz}, 6 \mathrm{kHz}$, and $8 \mathrm{kHz}$, respectively) was performed at octave or semi-octave frequencies under air conduction and at octave frequencies from 0.25 to $4 \mathrm{kHz}$ under bone conduction using a manual audiometer (GSI-Grason-stadler, USA) with TDH-50P supra-aural earphones (Telephonics, Farmingdale, USA). EHF audiometry (at $9 \mathrm{kHz}$, $10 \mathrm{kHz}, 11.5 \mathrm{kHz}, 12.5 \mathrm{kHz}, 14 \mathrm{kHz}, 16 \mathrm{kHz}, 18 \mathrm{kHz}$ and $20 \mathrm{kHz}$ ) was determined under air conduction using a calibrated audiometer (GSI-Grason-stadler, USA) with HDA-200 high frequency earphones (Sennheiser, Wedemark, Germany). The threshold was defined as the lowest decibel level at which the subject responded for at least $50 \%$ of the stimulus duration in ascending or descending presentations (ANSI, 2004) [19]. All audiometry equipment was calibrated according to ISO389-5 (International Organization for Standardization, 2006). A second measurement was performed to the participants 3 days after the initial test. Participants avoided the expose to loud noise ( $>80 \mathrm{~dB} \mathrm{HL}$ ) $24 \mathrm{~h}$ prior to the test.

\section{Statistical analyses}

Descriptive and quantitative analysis of difference associated with the independent variables were performed using SPSS 15 for Windows. Normality of the distribution was assessed using the Levine test. Comparisons of two independent samples (such as male versus female) were conducted either using two-tailed independent samples t-tests if the data were normally distributed revealed by the Levine test, or otherwise using the nonparametric rank-sum test (such as the hearing threshold). When the responsive rate to frequency didn't exceed $20 \%$, the hearing threshold value was not included. In all tests, $p<0.05$ was considered to be significant.

\section{Results \\ Study population}

A total of 162 healthy participants were enrolled in this study, and grouped into five groups based on their ages: $21 \sim 30$ years, 23 participants (46 ears) including 14 males and 9 females; $31 \sim 40$ years, 25 participants (50 ears) with 16 males and 9 females; $41 \sim 50$ years, 44 participants (88 ears) with 23 males and 21 females; $51 \sim 60$ years, 39 participants (78 ears) with 19 males and 20 
females; $61 \sim 70$ years, 31 participants (62 ears) with 21 males and 10 females. There was no gender difference within each age group, nor individual difference between the right and the left ear on the pure-tone hearing thresholds at the frequencies from 0.25 to $20 \mathrm{kHz}$.

\section{Conventional pure tone audiometry}

No reliable gender difference was seen in each group on hearing thresholds at the frequencies from 0.25 to $2 \mathrm{kHz}$. However, by merging different age groups, a significant difference $(p<0.05)$ on the mean thresholds was noticed between the $21 \sim 50$ and $51 \sim 70$ years old. The mean thresholds at $4 \mathrm{kHz}$ was significantly different from each other when compared in pair (all $p<0.05$ ), except for the comparison between the $21 \sim 30$ and the $31 \sim 40$ group. In addition, consistent threshold shifts at the frequencies of 6 and 8 $\mathrm{kHz}$ were seen among groups. The hearing thresholds at the frequencies of 6 and $8 \mathrm{kHz}$ were significantly elevated in groups above 31 years old, and showed an age-dependency starting from 51 years old $(p<0.05)$. These findings suggested that hearing ability of healthy participants declined at the frequencies of 0.25 to $2 \mathrm{kHz}$ from the age of $51,4 \mathrm{kHz}$ form the age fo 41 , and 6 to $8 \mathrm{kHz}$ from the age of 31. Table 1 depicted the hearing thresholds of subjects at various frequencies by age groups. The hearing ability at conventional high frequencies from 4 to $8 \mathrm{kHz}$ declined from 51 years old, and the hearing thresholds ascended to $25 \sim 40 \mathrm{~dB}$ HL.

\section{Extended high frequency audiometry}

The hearing thresholds in different age groups were compared and the results showed a significant difference at all frequencies from 9 to $16 \mathrm{kHz}(p<0.001)$ (Table 1). The hearing threshold at $9 \mathrm{kHz}$ was significantly increased starting from the $31 \sim 40$ group and worsened to $50 \mathrm{~dB}$ HL from 51 years old $(p<0.05)$, the same as the situation at the 6 and $8 \mathrm{kHz}$. At the frequencies of 10 $\mathrm{kHz}, 11.5 \mathrm{kHz}$, and $12.5 \mathrm{kHz}$, the average hearing thresholds between groups were significantly different from each other with the exception of the $31 \sim 40$ group comparing with the $41 \sim 50$ group. The hearing deterioration at the frequency of $14 \mathrm{kHz}$ was quite similar to the changes at frequencies of 6,8 and $9 \mathrm{kHz}$. At the frequency of $16 \mathrm{kHz}$, the average hearing threshold of 25 $\mathrm{dB}$ HL in the $21 \sim 30$ group was significantly better than those in 31-60 age groups, and the threshold of $50 \mathrm{~dB}$ $\mathrm{HL}$ in the $31 \sim 40$ group was better than those of $55 \mathrm{~dB}$ $\mathrm{HL}$ in the $41 \sim 60$ age group $(p<0.05)$. These results showed that hearing at EHF degenerated in subjects starting from their $30 \mathrm{~s}$, and dominating in their $50 \mathrm{~s}$ and older (Fig. 1). The hearing thresholds of EHF were less than $26 \mathrm{~dB}$ HL before 30 years old. The means of threshold values were up to $75 \mathrm{~dB} \mathrm{HL}$ with aging. It is worth noting that less than $20 \%$ response was recorded at 16 $\mathrm{kHz}$ in the $61 \sim 70$ group as well as at the 18 and $20 \mathrm{kHz}$ in the groups older than 31 years old, suggesting that hearing ability declined at higher frequencies even in healthy population.

The sensitivity at EHF decreased as the frequency increased in each age group, and it decreased with aging

Table 1 The statistics of hearing thresholds at frequencies of subjects grouped by age

\begin{tabular}{|c|c|c|c|c|c|}
\hline \multirow{2}{*}{$\begin{array}{l}\text { Frequency } \\
\text { (kHz) }\end{array}$} & \multicolumn{5}{|c|}{ Hearing threshold (dB HL) $M(Q L, Q U)$} \\
\hline & $21-30$ years & $31-40$ years & 41-50 years & $51-60$ years & $61-70$ years \\
\hline $0.25-2$ & $10.00(6.50,10.00)$ & $7.50(5.00,11.25)$ & $10.00(8.75,15.00)$ & $13.75(10.00,22.50)^{* \Delta} \boldsymbol{\Lambda}$ & $18.75(11.25,32.50)^{* \Delta}$ \\
\hline 4 & $10.00(6.50,10.00)$ & $10.00(5.00,20.00)$ & $15.00(10.00,25.00)^{*}$ & $25.00(15.00,50.00)^{*_{\Delta} \Delta}$ & $40.00(25.00,60.00)^{* \Delta} \boldsymbol{\Delta .}$ \\
\hline 6 & $10.00(6.50,10.00)$ & $15.00(7.50,35.00)^{*}$ & $17.50(15.00,25.00)^{*}$ & $40.00(15.00,60.00)^{* \Delta} \boldsymbol{\Lambda}$ & $45.00(35.00,55.00)^{* \Delta} \boldsymbol{\Lambda}$ \\
\hline 8 & $10.00(6.50,10.00)$ & $15.00(5.00,30.00)^{*}$ & $20.00(10.00,25.00)^{*}$ & $40.00(15.00,60.00)^{* \Delta} \boldsymbol{\Delta}$ & $50.00(35.00,60.00)^{* \Delta} \boldsymbol{\Lambda}$ \\
\hline 9 & $10.00(10.00,15.00)$ & $15.00(10.00,47.50)^{*}$ & $27.50(16.25,40.00)^{*}$ & $50.00(28.75,75.00)^{* \Delta} \boldsymbol{\Delta}$ & $60.00(55.00,70.00)^{*_{\Delta}} \boldsymbol{\Lambda}$ \\
\hline 10 & $10.00(10.00,15.00)$ & $30.00(12.50,45.00)^{*}$ & $32.50(20.00,50.00)^{*}$ & $60.00(28.75,75.00)^{*_{\Delta}} \boldsymbol{\Lambda}$ & $70.00(60.00,80.00)^{* \Delta} \boldsymbol{\Delta}$ \\
\hline 11.5 & $10.00(10.00,20.00)$ & $40.00(17.50,52.50)^{*}$ & $45.00(30.00,63.75)^{*}$ & $62.50(36.25,80.00)^{* \Delta} \boldsymbol{\Delta}$ & $75.00(61.25,85.00)^{* \Delta} \boldsymbol{\Delta}$ \\
\hline 12.5 & $15.00(10.00,20.00)$ & $50.00(25.00,65.00)^{*}$ & $55.00(35.00,75.00)^{*}$ & $65.00(51.25,83.75)^{* \Delta} \boldsymbol{\Lambda}$ & $75.00(70.00,85.00)^{* \Delta} \boldsymbol{\Delta \cdot}$ \\
\hline 14 & $20.00(10.00,30.00)$ & $60.00(46.25,73.75)^{*}$ & $65.00(50.00,80.00)^{*}$ & $70.00(60.00,75.00)^{* \Delta} \boldsymbol{\Lambda}$ & $75.00(70.00,80.00)^{* \Delta}$ \\
\hline 16 & $25.00(10.00,45.00)$ & $50.00(35.00,55.00)^{*}$ & $55.00(50.00,60.00)^{* \Delta}$ & $55.00(55.00,60.00)^{* \Delta}$ & NA \\
\hline 18 & $20.00(10.00,30.00)$ & NA & NA & NA & NA \\
\hline 20 & $10.00(10.00,15.00)$ & NA & NA & NA & NA \\
\hline
\end{tabular}

*, significantly different $(p<0.05)$ from that of the $21-30$ group

$\Delta$, significantly different $(p<0.05)$ from that of the $31-40$ group

$\boldsymbol{\Delta}$, significantly different $(p<0.05)$ from that of the $41-50$ group

a, significantly different $(p<0.05)$ from that of the $51-60$ group

$M\left(Q_{L}, Q_{U}\right)$, Median (lower quartile, upper quartile)

NA, not applicable since the response was equivalent or smaller than $20 \%$ 


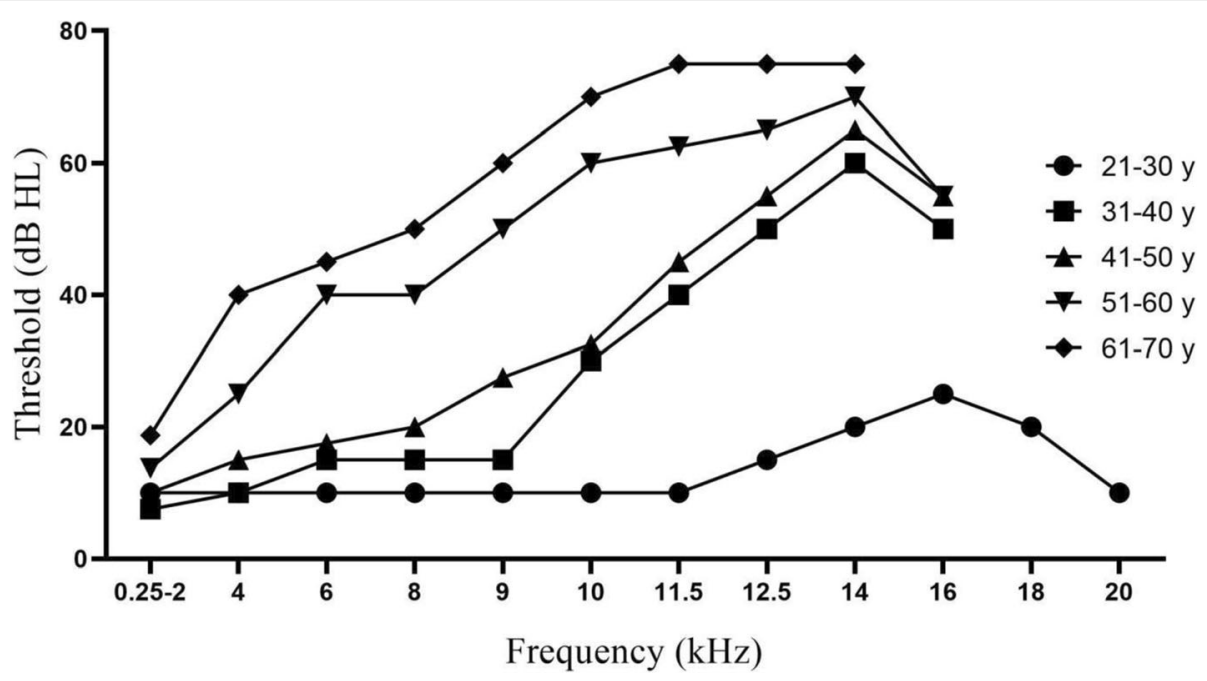

Fig. 1 Overview of hearing thresholds at frequencies from 0.25 to $20 \mathrm{kHz}$ of subjects grouped by age

for each frequency as well. Our results showed that all subjects aged below 30 years old were totally responsive at frequencies up to $16 \mathrm{kHz}$, while the responsiveness decreased to $52.2 \%$ at $20 \mathrm{kHz}$. More than $90 \%$ of the subjects aged $31 \sim 40$ years old were totally responsive at frequencies up to $14 \mathrm{kHz}$, while it decreased below $50 \%$ at $18 \mathrm{kHz}$. More than $90 \%$ of the ears in the $41 \sim 50$ group responded at frequencies up to $12.5 \mathrm{kHz}$, but comparatively similar percentage only occurred in the group older than 51 years old at frequencies up to 11.5 kHz. As shown in Table 2, these data demonstrated that the responsiveness of hearing in normal population decreased in a frequency and age dependent manner.

Moreover, no difference in the means of hearing thresholds between male and female subjects were seen nearly at all frequencies and in all age groups, except that gender differences $(p<0.05)$ could be found in the mean thresholds at frequencies of $4,6,8$, and $9 \mathrm{kHz}$ in the $41 \sim 50$ group, suggesting a possibly greater hearing loss in males at their 40s.

\section{Discussion}

Age related hearing loss is often gradual and progressed with subtle changes in an individual's ability to discriminate high pitches. Meanwhile, some patients also complain about difficulty in understanding speech under noisy environments. Nevertheless, no apparent impact on verbal communication had been observed due to the hearing loss in EHF [3]. Therefore, delays in identification and subsequent help-seeking for hearing damage are quite common, which may prevent early diagnosis of hearing loss and are associated with physical and mental handicap [20]. Hearing screening has been suggested to be a potential useful tool to get around some of the

Table 2 NormalizedPercentage of responses at various frequencies

\begin{tabular}{|c|c|c|c|c|c|}
\hline Frequency $(\mathrm{kHz})$ & $\begin{array}{l}21-30 \text { years } \\
\text { ( } 46 \text { ears) }\end{array}$ & $\begin{array}{l}31-40 \text { years } \\
\text { (50 ears) }\end{array}$ & $\begin{array}{l}41-50 \text { years } \\
\text { ( } 88 \text { ears) }\end{array}$ & $\begin{array}{l}51-60 \text { years } \\
\text { ( } 78 \text { ears) }\end{array}$ & $\begin{array}{l}61-70 \text { years } \\
\text { (62 ears) }\end{array}$ \\
\hline $0.25-2$ & 100.0 & 100.0 & 100.0 & 100.0 & 100.0 \\
\hline 4 & 100.0 & 100.0 & 100.0 & 100.0 & 100.0 \\
\hline 6 & 100.0 & 100.0 & 100.0 & 100.0 & 100.0 \\
\hline 8 & 100.0 & 100.0 & 100.0 & 100.0 & 100.0 \\
\hline 9 & 100.0 & 100.0 & 100.0 & 100.0 & 97.4 \\
\hline 10 & 100.0 & 100.0 & 100.0 & 100.0 & 97.4 \\
\hline 11.5 & 100.0 & 100.0 & 100.0 & 92.3 & 90.3 \\
\hline 12.5 & 100.0 & 100.0 & 93.2 & 82.1 & 74.2 \\
\hline 14 & 100.0 & 96.0 & 79.5 & 59.0 & 45.2 \\
\hline 16 & 100.0 & 64.0 & 38.6 & 30.8 & 16.1 \\
\hline 18 & 78.3 & 20.0 & 2.3 & 2.6 & 0.0 \\
\hline 20 & 52.2 & 8.0 & 2.3 & 0.0 & 0.0 \\
\hline
\end{tabular}


deferments. The American Speech Language Hearing Association (2011) suggested that adults' hearing should be screened in, at least, decade intervals before age 50 and in every 3 years thereafter, since individuals at their $50 \mathrm{~s}$ might seem to have healthy hearing due to their normal conventional audiometric thresholds, yet the early onset of hearing impairment might happen.

We examined the hearing thresholds at frequencies from 0.25 to $20 \mathrm{kHz}$ in the population claimed to have normal hearing abilities ranging from 20 to 70 years old in order to observe the potential age-related changes in their auditory system. As the hearing threshold at $4 \mathrm{kHz}$ was obviously increased in adult older than 50 with clinically normal hearing sensitivity, subjects with hearing thresholds lower than $20 \mathrm{~dB} \mathrm{HL}$ at up to $2 \mathrm{kHz}$ were included in this study. Our data demonstrated similarities in average thresholds at frequencies from 0.25 to $2 \mathrm{kHz}$ in subjects younger than 50 years old. However, the hearing thresholds increased predominantly starting from the age of 41 at $4 \mathrm{kHz}$, and from the age of 31 at 6 and $8 \mathrm{kHz}$. Therefore, we might conclude that the onset frequency of effects by aging were $4 \mathrm{kHz}$.

In this study, Fig. 1 demonstrated an overview of average hearing thresholds for each age group by frequencies. The average thresholds, which began to separate gradually from the adjacent groups at the frequencies below $14 \mathrm{kHz}$, were inversely proportional to the age of participants, possibly suggesting the aging of the auditory system. Moreover, our results showed that hearing ability at EHF declined beginning at 30 years of age, and became obvious at 50 years of age and later. These findings remarkably confirmed the notion that hearing thresholds at EHF could be more sensitive for early detection of the hearing damage than the conventional audiometric at lower frequencies [7, 21]. Meanwhile, it would be worth pointing out that the sensitivity of these EHF thresholds might decrease as the detecting frequency and participant's age increasing, since we observed a decrease in the response to EHF above $14 \mathrm{kHz}$ with an increase in both frequency and age. The percentage of response reached as high as $78.3 \%$ at $18 \mathrm{kHz}$ and $52.2 \%$ at $20 \mathrm{kHz}$ in their $20 \mathrm{~s}$. However, for groups with older participants, the percentage of response at 18 and $20 \mathrm{kHz}$ did not exceed $20 \%$, which is consistent with the previous investigations on subjects below 40 years old [22]. The overview of the responses at EHF of subjects ranging from 20 to 70 years old at a 10-year interval in the current study revealed the possibility that the clinical value of response to EHF might decrease as the frequency increase, and $14 \mathrm{kHz}$ should be an optional choice.

Although studies suggested a potential gender difference in the hearing loss, with males earlier than females [23, 24], Wiley et al. reported hearing abilities among men and women were generally similar based on their observation of hearing thresholds at $0.5,1,2$, and $8 \mathrm{kHz}$ in a large population [25]. Consistently, here in our study, no significant gender difference of hearing thresholds within each age group was observed at most of the frequencies from 0.25 to $20 \mathrm{kHz}$, leaving only the $41 \sim$ 50 group at the frequencies of 4, 6, 8, and $9 \mathrm{kHz}$. However, it would still be plausible to claim that aging process of hearing system might be different in males and females, since other risk factors such as exposure to noise, smoking, and alcoholic abuse [19] that were excluded in the current study.

The current findings on thresholds at EHF, as well as previous studies describing their use, demonstrate the fact that EHF audiometry should be taken into consideration as a necessary and routine test to diagnose and monitor hearing damage. Early prediction and intervention in the potential population, such as medication dose change or proper use of hearing protection for the ototoxic effect and noise exposure, might ease or even cease the development of hearing loss [19, 26]. Furthermore, taking into consideration that hearing problems may exacerbate psycho-social declines, whereas age-related psycho-social issues may aggravate hearing impairment, it is important to further investigate hearing loss in aging adults and their effects. Therefore, our results on hearing thresholds at EHF in normal population might serve the need for future clinical diagnosis and laboratory research.

This study had limitations. The number of subjects from a single medical center was limited, and it could not fully reflect the epidemiological characteristics of age-related hearing changes. On the other hand, we detected the hearing thresholds at frequencies from 0.25 to $20 \mathrm{kHz}$ in different age groups at the same period. In addition, no long-term follow-up was conducted for the same age group. Future research should involve multicentre cohort study over long term to determine the normal range of EHF deterioration. To establish the age-specific norm, more research is needed as well.

\section{Conclusion}

This study revealed that hearing thresholds at EHF from 9 to $20 \mathrm{kHz}$ were more sensitive than at frequencies below $8 \mathrm{kHz}$ towards the prediction of hearing loss, and showed clear age-dependency. Both hearing thresholds at EHF and the upper-frequency limit deteriorated with aging and elevation of the frequency. The results of this study also demonstrated reproducibility in measuring hearing thresholds at EHF, indicating that the EHF audiometry might be a reliable tool in monitoring the early etiopathogenesis of auditory diseases. 


\section{Abbreviations}

EHF: Extended high frequency; PTA: Pure tone average; NIHL: Noise-induced hearing loss

\section{Acknowledgements}

N/A

\section{Authors' contributions}

Mingming Wang contributed by analysis of data and drafted the manuscript. Yu Ai performed the collection and preservation of original data. Yuechen Han contributed by concept of idea, concept of study design. Zhaomin Fan reviewed and analyzed the data. Peng Shi contributed by concept of idea and editions of manuscript. Haibo Wang completed the study design and analyzed the data. All authors read and approved the final manuscript.

\section{Funding}

This work was supported by grants from the Key Technology Research and Development Program of Shandong (2019GSF108248), and Taishan Scholars Program of Shandong Province (No.ts20130913).

\section{Availability of data and materials}

The raw datasets generated and analysed during the current study are available from the corresponding author on reasonable request.

\section{Declarations}

Ethics approval and consent to participate

This study was permitted by the Ethics Committee of Shandong Provincial ENT Hospital.

\section{Consent for publication}

N/A

\section{Competing interests}

The authors declare that they have no competing interests.

\section{Author details}

${ }^{1}$ Department of Otorhinolaryngology Head and Neck Surgery, Shandong Provincial ENT Hospital, Cheeloo College of Medicine, Shandong University, Jinan, China. ${ }^{2}$ Department of Clinical Audiology, Shandong Provincial ENT Hospital, Cheeloo College of Medicine, Shandong University, Jinan, China. ${ }^{3}$ Department of Breast and Thyroid Surgery, Shandong Provincial Hospital Affiliated to Shandong First Medical University, 324 Jingwu Road, Jinan, China.

\section{Received: 15 March 2021 Accepted: 19 July 2021}

Published online: 26 August 2021

\section{References}

1. Chauhan RS, Saxena RK, Varshey S. The role of ultrahigh-frequency audiometry in the early detection of systemic drug-induced hearing loss. Ear Nose Throat J. 2011;90(5):218-22. https://doi.org/10.1177/0145561311 09000506.

2. Mehrparvar AH, Mirmohammadi SJ, Ghoreyshi A, et al. High-frequency audiometry: a means for early diagnosis of noise-induced hearing loss. Noise Health. 2011;13(55):402-6. https://doi.org/10.4103/1463-1741.90295.

3. Vielsmeier $V$, Lehner A, Strutz J, et al. The relevance of the high frequency audiometry in tinnitus patients with Normal hearing in conventional puretone audiometry. Biomed Res Int. 2015;2015:302515.

4. Mar LV, Ithzel MV, Julio L, et al. Examination of Hearing in a Rheumatoid Arthritis Population: Role of Extended-High-Frequency Audiometry in the Diagnosis of Subclinical Involvement. Scientifica (Cairo). 2016;2016:5713283.

5. Dreschler WA, Hulst RJvd, Tange RA, et al. The role of high-frequency audiometry in early detection of ototoxicity. Audiology. 1985;24(6):387-95. https://doi.org/10.3109/00206098509078358.

6. Jacobson EJ, Downs MP, Fletcher JL. Clinical findings in high frequency thresholds during known ototoxic drug usage. J Aud Res. 1969;9:379-85.

7. Ahmed HO, Dennis JH, Badran O, Ismail M, Ballal SG, Ashoor A, et al. Highfrequency $(10-18 \mathrm{kHz})$ hearing thresholds: reliability, and effects of age and occupational noise exposure. Occup Med. 2001;51(4):245-58. https://doi. org/10.1093/occmed/51.4.245.
8. Fausti SA, Frey RH, Erickson DA, Rappaport BZ, Cleary EJ, Brummett RE. A system for evaluating auditory function from 8000-20000 Hz. J Acoust Soc Am. 1979;66(6):1713-8. https://doi.org/10.1121/1.383643.

9. Antonioli CAS, Momensohn-Santos TM, Benaglia TAS. High-frequency audiometry hearing on monitoring of individuals exposed to occupational noise: a systematic review. Int Arch Otorhinolaryngol. 2016;20(3):281-9. https://doi.org/10.1055/s-0035-1570072.

10. Shaw GM, Jardine CA, Fridjhon P. A pilot investigation of high-frequency audiometry in obscure auditory dysfunction (OAD) patients. Br J Audiol. 1996;30(4):233-7. https://doi.org/10.3109/03005369609076770.

11. Osterhammel D. High frequency audiometry clinical aspects. Scand Audiol. 1980;9(4):249-56. https://doi.org/10.3109/01050398009076360.

12. Osterhammel D, Osterhammel P. High-frequency audiometry: age and sex variations. Scand Audiol. 1979;8(2):73-80. https://doi.org/10.3109/010503 97909076304

13. Fletcher JL. Reliability of high-frequency thresholds. J Audiol Res. 1965;5: 133-7.

14. Henry KR, Fast GA. Ultrahigh-frequency auditory thresholds in young adults: reliable responses up to $24 \mathrm{kHz}$ with a quasi-free-field technique. Audiology. 1984;23(5):477-89. https://doi.org/10.3109/00206098409070087.

15. Stelmachowicz PG, Beauchaine KA, Kalberer A, Langer T, Jesteadt W. The reliability of auditory thresholds in the 8 - to $20-\mathrm{kHz}$ range using a prototype audiometer. J Acoust Soc Am. 1988;83(4):1528-35. https://doi.org/1 0.1121/1.395909.

16. Zhou B, Green DM. Reliability of pure-tone thresholds at high frequencies. J Acoust Soc Am. 1995;98(2):828-36. https://doi.org/10.1121/1.413509.

17. Schmuziger N, Probst R, Smurzynski J. Test-retest reliability of pure-tone thresholds from 0.5 to $16 \mathrm{kHz}$ using Sennheiser HDA 200 and Etymotic research ER-2 earphones. Ear Hear. 2004;25(2):127-32. https://doi.org/10.1 097/01.AUD.0000120361.87401.C8.

18. Joo Y, Cruickshanks KJ, Klein BEK, Klein R, Hong OS, Wallhagen MI. The contribution of ototoxic medications to hearing loss among older adults. J Gerontol A Biol Sci Med Sci. 2020;75(3):561-6. https://doi.org/10.1093/ gerona/glz166.

19. Valiente AR, Trinidad A, Garc'ıa Berrocal JR, et al. Extended high-frequency (9-20 kHz) audiometry reference thresholds in 645 healthy subjects. Int J Audiol. 2014:53:531-45.

20. Mazurek B, Olze H, Haupt H, Szczepek AJ. The more the worse: the grade of noise-induced hearing loss associates with the severity of tinnitus. Int J Environ Res Public Health. 2010;7(8):3071-9. https://doi.org/10.3390/ ijerph7083071.

21. Schmuziger N, Patscheke J, Probst R. An assessment of threshold shifts in nonprofessional pop/rock musicians using conventional and extended high-frequency audiometry. Ear Hear. 2007;28(5):643-8. https://doi.org/10.1 097/AUD.0b013e31812f7144.

22. Northern JL, Downs MP, Rudmose W, Glorig A, Fletcher JL. Recommended high frequency audiometric threshold levels (8000-18000 Hz). Acoust Soc Am. 1972;52(2B):585-95. https://doi.org/10.1121/1.1913149.

23. Davis A, McMahon CM, Pichora-Fuller KM, et al. Aging and hearing health: the life-course approach. Gerontologist. 2016;56(S2):S256-67. https://doi. org/10.1093/geront/gnw033.

24. Hoffman HJ, Dobie RA, Losonczy KG, Themann CL, Flamme GA. Declining prevalence of hearing loss in US adults aged 20 to 69 years. JAMA Otolaryngol Head Neck Surg. 2017;143(3):274-85. https://doi.org/10.1001/ja maoto.2016.3527

25. Wiley TL, Chappell R, Carmichael L, Nondahl DM, Cruickshanks KJ. Changes in hearing thresholds over 10 years in older adults. J Am Acad Audiol. 2008; 19(4):281-371. https://doi.org/10.3766/jaaa.19.4.2.

26. Valiente $A R$, Fidalgo AR, Villarreal IM, et al. Extended high-frequency audiometry $(9,000-20,000 \mathrm{~Hz})$. Usefulness in audiological diagnosis. Acta Otorrinolaringol Esp. 2016;67:40-4.

\section{Publisher's Note}

Springer Nature remains neutral with regard to jurisdictional claims in published maps and institutional affiliations. 